\title{
Colorimetric Analysis on Flocculation of Bioinspired Au Self-Assembly for Biophotonic Application
}

\author{
Wan-Joong Kim, ${ }^{1}$ JaeTae Seo, ${ }^{2}$ Chil Seong Ah, ${ }^{1}$ Jasmine Austin, ${ }^{2}$ Shanghee Kim, ${ }^{1}$ \\ Ansoon Kim, ${ }^{1}$ Gun Yong Sung, ${ }^{1}$ and Wan Soo Yun $^{3}$ \\ ${ }^{1}$ Biotechnology Convergence Technology Research Department, Electronics and Telecommunications Research Institute,
Daejeon 305-700, South Korea
${ }^{2}$ Department of Physics, Hampton University, Hampton, VA 23668, USA
${ }^{3}$ Division of Advanced Technology, Korea Research Institute of Standards and Science, Daejeon 305-340, South Korea
}

Correspondence should be addressed to JaeTae Seo, jaetae.seo@hamptonu.edu

Received 6 November 2008; Accepted 28 February 2009

Recommended by Do Kim

Gold nanoparticles exhibited strong surface plasmon absorption and couplings between neighboring particles within bioactivated self-assembly modified their optical properties. Colorimetric analysis on the optical modification of surface plasmon resoanance (SPR) shift and flocculation parameter functionalized bioinspired gold assembly for biophotonic application. The physical origin of bioinspired gold aggregation-induced shifting, decreasing, or broadening of the plasmon absorption spectra could be explained in terms of dynamic depolarization, collisional damping, and shadowing effects.

Copyright ( $) 2009$ Wan-Joong Kim et al. This is an open access article distributed under the Creative Commons Attribution License, which permits unrestricted use, distribution, and reproduction in any medium, provided the original work is properly cited.

\section{Introduction}

Integrated systems of plasmonic nanometals and biomolecules are of great interest for biophotonic applications because of their optical colorimetric properties and distinctive microscopic structures. It is well known that the extinction spectra of surface plasmon resoanance (SPR) or intraband transitions of monodispersed nanometals are tunable, from visible to near infrared region, by controlling the individual morphologies and structures that confine their dielectric functions. A combination of the optical tunability and bioinspired self-assembly of nanometals through biospecific interactions functionalizes nanometals for photonic applications. Couplings between bioinspired nanometal selfassembly modify optical properties. Mole sensitivity of bioactivators that inspire $\mathrm{Au}$ nanometal self-assembly has been introduced down to less than $\sim 10 \mathrm{nM}$ by monitoring SPR modification [1]. The functionalized biosensors could also be coupled with Raman for identifying bio activators. $\mathrm{Au}$ nanoparticles for the biophotonic applications were chosen because they have good biocompatibility, strong and tunable SPR, controllable homogeneous morphology, and weak photodegradation [2]. The integrated material systems of plasmonic nanometals and biomolecules for biophotonic applications were avidin-inspired biotin attachedAu assembly and DNA-linked Au-hybridization, because they have high affinity and biospecific interaction [3-6]. Recent investigations on mass sensitivity of bioactivators for $\mathrm{Au}$ nanometal self-assembly were conducted mostly based on SPR peak red shift. However, the physical origin of SPR spectral shift, decrease, and broadening of bioinspired nanometal-assembly can be explained in terms of dynamic depolarization, radiation damping, and shadowing effects. Therefore, it is suggested that combinational analysis of both flocculation parameter [7-9] and peak shift of SPR on bioactivated nanometals would closely track any aggregation process [1], and might promote the bioplasmonic material system for photonic applications in the diagnosis of pathogenic and genetic diseases [10-12].

\section{Experiment}

Gold nanoparticles without any organic surfactants [1316] and biotin (vitamin H)-linked thiol (BLT)-attached 
gold nanometals $[8,17]$ were prepared by the literature procedures. The BLT was synthesized by simply coupling biotin with 2-mercaptoethylamine after activation of the carboxylic acid group of biotin with pentafluorophenol. Average diameters of near monodispersed gold nanoparticles were from $\sim 4.5 \mathrm{~nm}$ to $\sim 22 \mathrm{~nm}$ within electrostatic dipole approximation. Complexation of $2-\mathrm{mL}$ gold aqueous solution and $0.6-\mathrm{mL}$ dipotassium bis(p-sulfonatophenyl) phenylphosphane dihydrate (BSPP) were shaken gently for 14 hours at room temperature for stabilizing gold colloidal particles [18-20]. Mixture of $0.1 \mathrm{~mL}$ of $1 \mathrm{mM}$ BLT with BSPP-capped gold solution was incubated for 4 hours at room temperature for preparing BLT-attached gold solutions. Residual of BSPP and BLT from the BLT-attached gold solution was completely removed. Bovine serum albumin (BSA) $(0.05 \% \mathrm{w} / \mathrm{v})$ was added to the BLT-attached gold nanoparticle solution to minimize nonspecific adsorption of proteins [21-23]. A stock solution of streptavidin $\left(10^{-5} \mathrm{M}\right)$ was prepared in deionized water and stored at near-freezing temperature. The concentration of streptavidin to cause gold nanoparticle aggregations was similar to Sastry et al.'s report [8]. Addition of $0.1-\mathrm{mL}$ of streptavidin solution $\left(10^{-5} \mathrm{M}\right)$ at room temperature into $1-\mathrm{mL}$ of BLT $(1 \mathrm{mM})$-attached mixture of $2-\mathrm{mL}$ gold aqueous solution and $0.6-\mathrm{mL}$ BSPP could lead to their aggregations with biospecific binding. Biotin-streptavidin interaction is biomolecular recognition of $\mathrm{Ka} \sim 10^{15} \mathrm{moL}^{-1}$ as a high affinity, and is stable over a wide range of $\mathrm{pH}$ and temperature [3-6]. Streptavidin is a tetrameric protein, and coordinates to the biotin ligands from Au colloidal nanoparticles which lead to crosslinking of the particles [8]. The mixture of the inducedaggregation of the gold colloidal nanoparticles was stirred for 10 minutes and stored at room temperature for microscopic and spectroscopic analysis.

The DNA-linked $\mathrm{Au}$ nanoparticles also interact biospecifically and inspire self-hybridization that creates surface plasmon coupling between neighboring particles, and modifies their optical properties. For DNA-linked Au-hybridization $[15,24]$, Au nanoparticles with $\sim 12-\mathrm{nm}$ average diameter were prepared by the citrate reduction of $\mathrm{HAuCl}_{4}$, and were chemically modified with $5^{\prime}$-or $3^{\prime}$ alkythiol-capped 12-base oligonucleotides (Au-S-5'-DNA or Au-S-3'-DNA). A mixture solution with $\sim 1 / 220$ mole ratio of $14 \mathrm{nM} \mathrm{Au}$ nanoparticles $(6.1 \mathrm{~mL})$ to $5^{\prime}$ - or $3^{\prime}$-DNA containing thiol functional group $(1.59 \mathrm{~mL})$ was shaken for 20 hours at room temperature. The Au-S-5'-DNA $(0.2 \mathrm{~mL})$ and Au-S-3'-DNA ( $0.2 \mathrm{~mL})$ - 12-base oligonucleotides were hybridized to a series of $20-\mu \mathrm{L}$ oligonucleotide linkers ranging from 24 to 72 base pairs in the length of $\sim 8-24 \mathrm{~nm}$. For the DNA-linked gold nanoparticle solutions, each $20-\mu \mathrm{L}$ of the 36.5- $\mu \mathrm{M}$ DNA linker solution $(24,48,72$ base linker) was added to $790-\mu \mathrm{L}$ of DNA-modified gold nanoparticle solution in $0.3 \mathrm{M} \mathrm{NaCl}, 10 \mathrm{mM}$ phosphate buffer ( $\mathrm{pH} 7$ ), and $0.01 \%$ azide solution. In the DNA-driven nanometal hybridization process, oligonucleotide-functionalized $\mathrm{Au}$ nanoparticles were exposed to free oligonucleotide, one end of which was harmonizing to the DNA on half of the $\mathrm{Au}$ nanoparticles, the other end of which was matching to the DNA on the rest of the spherical nanoparticles. The different rates of DNA hybridization were associated with the three oligonucleotide linkers of 24,48 , and 72 base pairs. The DNA hybridization pulled the nanoparticles together and aggregated them each other. The resulting optical spectra of DNA-linked Au-hybridization differed significantly from those of noninteracting and monodispersed particles.

\section{Result and Discussion}

Schematic diagrams, transmission electron microscopic images, and typical absorption spectra of monodispersed nanoparticles and bioinspired Au aggregations were shown in Figures 1(a) and 1(b). The schematic diagrams displayed the avidin-mediated assembly of biotin-attached gold nanoparticles $[1,17,25]$. Their typical absorption spectra showed SPR shift from $519 \mathrm{~nm}$ with bare $\mathrm{Au}$ and $526 \mathrm{~nm}$ with BLT-attached Au nanoparticle solution to $550 \mathrm{~nm}$ by adding $10^{-5}-\mathrm{M}$ (strept)avidin solution. The binding of (strept)avidin to the BLT-attached Au nanoparticles was completed within $\sim 10$ minutes at room temperature. The spectral change of SPR for BLT-attached Au nanoparticle is owing to dielectric environment change, and that for self-assembly is because of aggregated size and coupling between the particles. The strong aggregation of avidinmediated assembly of the BLT-attached Au nanoparticles was additionally confirmed by TEM as shown in Figure 1(c). Similarly, schematic diagram $[15,24,26]$, typical absorption spectra, and TEM images of DNA-linked gold nanoparticle assembly were shown in Figures 2(a), 2(b), and 2(c), respectively. The schematic diagram explains three different linker lengths of 24-, 48-, 72-base DNA-conjugated Au assembly through hybridization of each 12-base DNA-conjugated $\mathrm{Au}$ nanoparticles $[15,24]$. Large spectral changes and assembly conditions were evidenced by their optical absorption and TEM images.

The combinational analysis of both flocculation parameter and peak shift of SPR on bioactivated Au nanometals was shown in Figures 1(d) and 1(e). The flocculation parameter was evaluated by following Mayya et al.'s process [28], which was depicted in the order of extinction normalizations of Au nanoparticles and assembly, subtraction of the spectra of $\mathrm{Au}$ nanoparticles from that of bioinspired $\mathrm{Au}$ assembly, and extinction integration between flocculation resonance $[7,29]$ at $600 \mathrm{~nm}$ and cutoff wavelength at $800 \mathrm{~nm}$ that encountered the longitudinal component up to nanoparticle diameters $\sim 56 \mathrm{~nm}[7,8]$.

Maximum changes of extinction and SPR peaks between $\mathrm{Au}$ and Au-biotin-avidin were $\sim 0.3$ and $\sim 1.2$, and $6 \mathrm{~nm}$ and $53 \mathrm{~nm}$, respectively, with particle concentrations of $\sim 1 \times 10^{-5} \mathrm{~mol} / \mathrm{m}^{3}$ and average diameters of $\sim 4$ to $\sim 23 \mathrm{~nm}$. Shifting of the SPR peak of colloidal special AU nanoparticles well explained by the Mie theory [30], and that of extinction spectra of self-assemblies was known as a collective nature of the aggregate response [31]. The lowering extinction of $\mathrm{Au}$ self-assembly could be attributed to a shadowing effect [31]. In contrast, smaller Au nanoparticle assemblies, for example, $\mathrm{D} \sim 4.5 \mathrm{~nm}$, did not exhibit the lowering extinction compared with that of bare Au colloidal particles that implied a shortening collisional dephasing rate of Au self-assemblies 


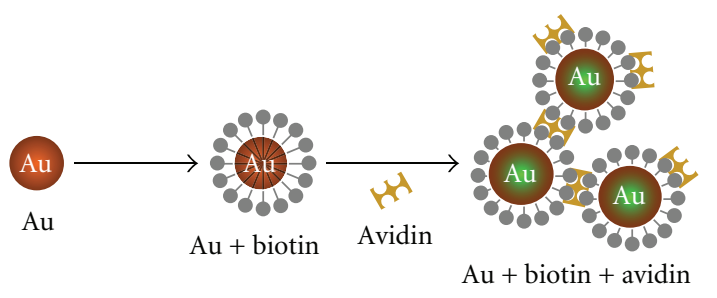

(a)

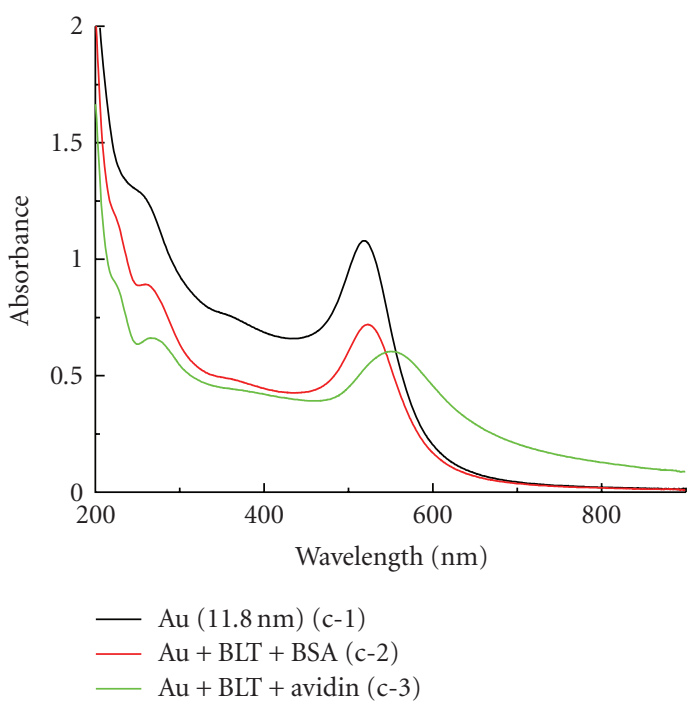

(b)
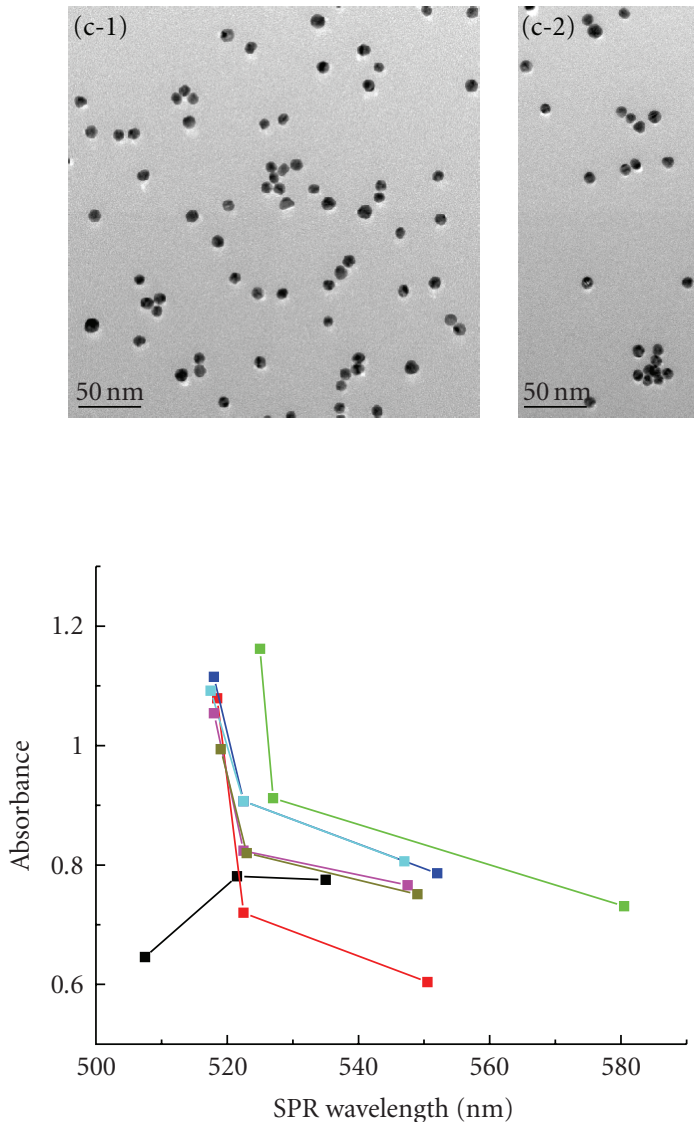

$\mathrm{Au} / \mathrm{Au}+\mathrm{BLT} / \mathrm{Au}+\mathrm{BLT}+$ avidin

$--4.5 \mathrm{~nm} \quad--15.2 \mathrm{~nm}$

$-11.8 \mathrm{~nm} \quad-=-15.8 \mathrm{~nm}$

$--14.8 \mathrm{~nm} \quad--23.1 \mathrm{~nm}$

$-15.1 \mathrm{~nm}$

(d)

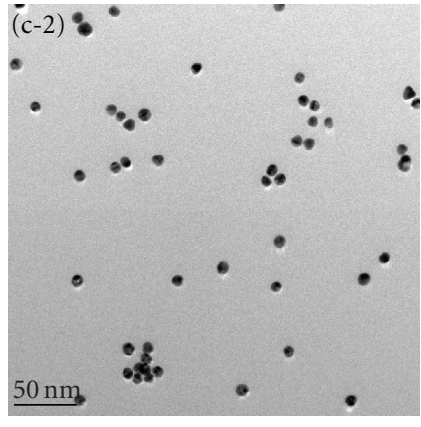

(c)

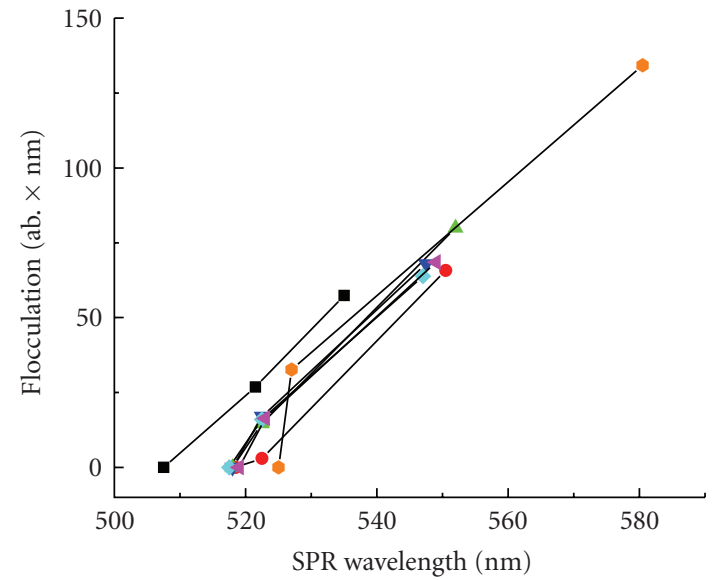

$\mathrm{Au} / \mathrm{Au}+\mathrm{BLT} / \mathrm{Au}+\mathrm{BLT}+$ avidin

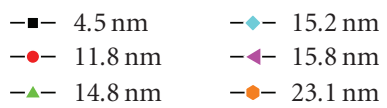

(e)

Figure 1: (a) Schematic diagram [1, 17, 25], (b) typical absorption spectra, (c) typical TEM images of bare Au, Au+Biotin, and Au+Biotin+Avidin, (d) absorbance as a function of SPR peak wavelength, and (e) flocculation as a function of SPR peak wavelength of bare $\mathrm{Au}, \mathrm{Au}+\mathrm{Biotin}$, and $\mathrm{Au}+$ Biotin+Avidin. 

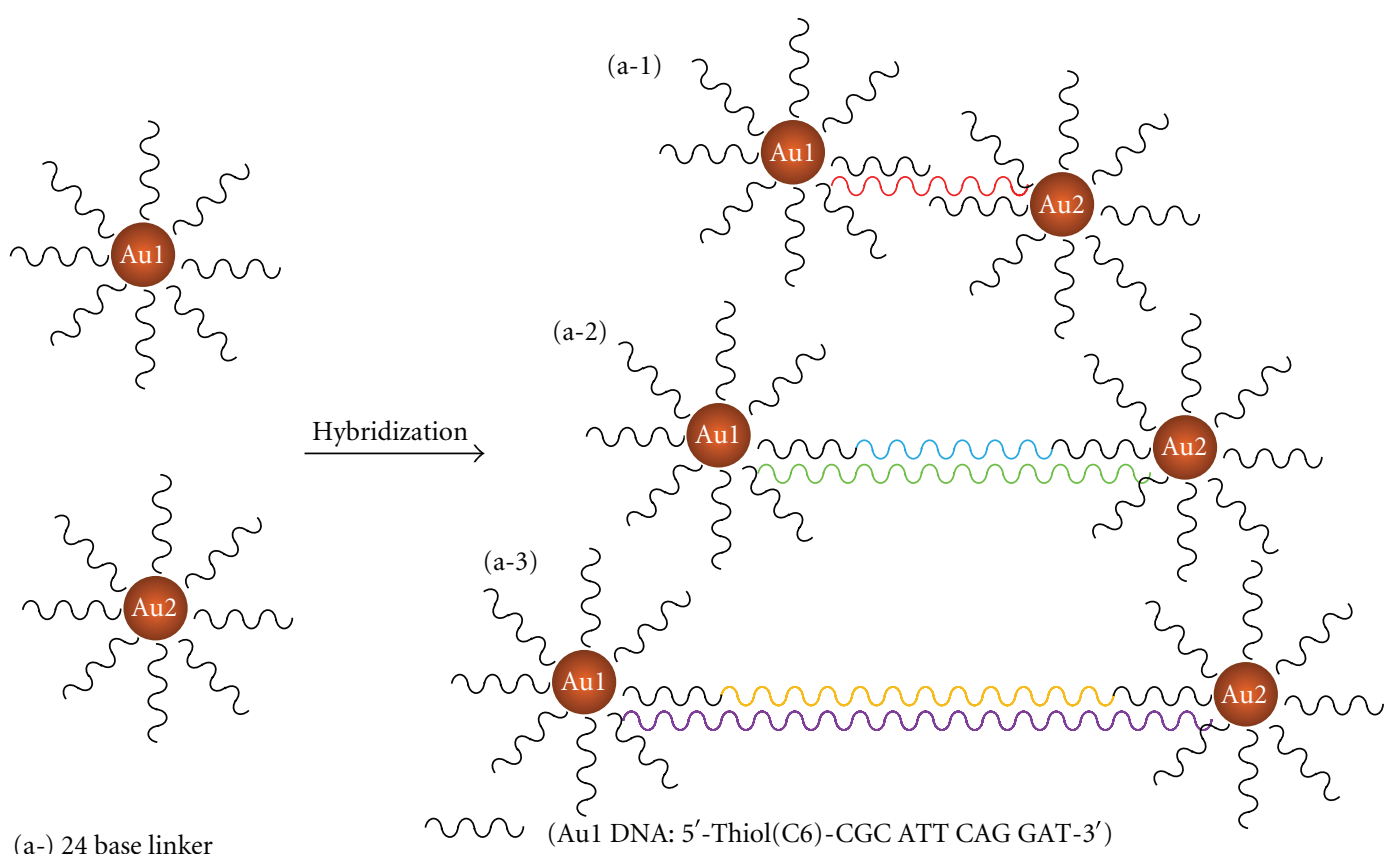

(a-) 24 base linker

$\sim \sim$ (Au1 DNA: 5'-Thiol(C6)-CGC ATT CAG GAT-3')

5'TAC GAG TTG AGA ATC CTG AAT GCG 3' (Au2 DNA: 5'-TCT CAA CTC GTA-Thiol(C3)-3')

(a-2) 48 base linker

5’TAC GAG TTG AGA CCG TTA AGA CGA GGC AAT CAT GCA ATC CTG AAT GCG 3’

(a-3) 72 base linker 3'GGC AAT TCT GCT CCG TTA GTA CGT5'

5’TAC GAG TTG AGA CCG TTA AGA CGA GGC AAT CAT GCA TAT ATT GGA CGC TTT ACG GAC AAC ATC CTG AAT GCG3' 3’ GGC AAT TCT GCT CCG TTA GTA CGT ATA TAA CCT GCG AAA TGC CTG TTG 5'

(a)

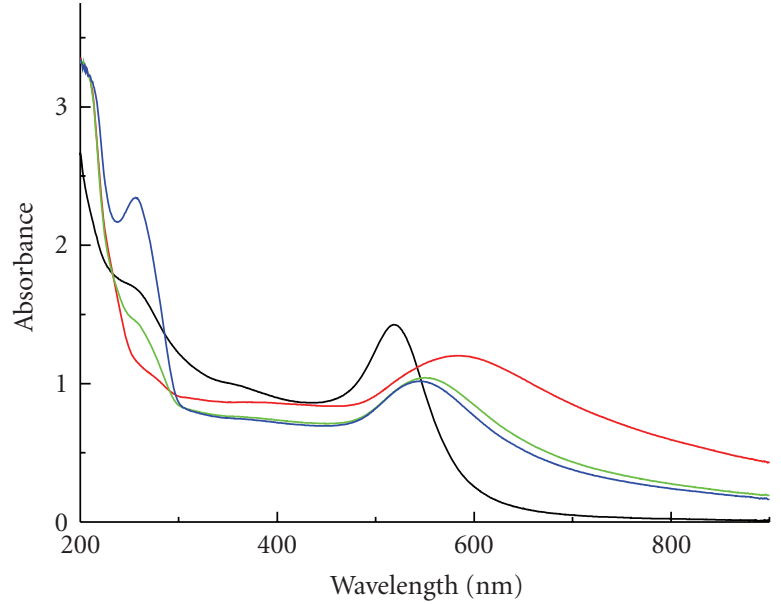

\begin{tabular}{|l|c|c|c|c|c|}
\hline & Sample & SPR $(\mathrm{nm})$ & Peak ab. & Floc. $(\mathrm{A} \times \lambda)$ & \\
\hline- & Au $(\sim 12 \mathrm{~nm})$ & $\sim 519$ & $\sim 1.43$ & $\sim 0$ & $(\mathrm{c}-1)$ \\
\hline- & Au-DNA 24 & $\sim 584$ & $\sim 1.2$ & $\sim 135$ & (c-2) \\
\hline- & Au-DNA 48 & $\sim 550$ & $\sim 1.04$ & $\sim 81$ & $(\mathrm{c}-3)$ \\
\hline- & Au-DNA 72 & $\sim 545$ & $\sim 1.02$ & $\sim 72$ & $(\mathrm{c}-4)$ \\
\hline
\end{tabular}

(b)
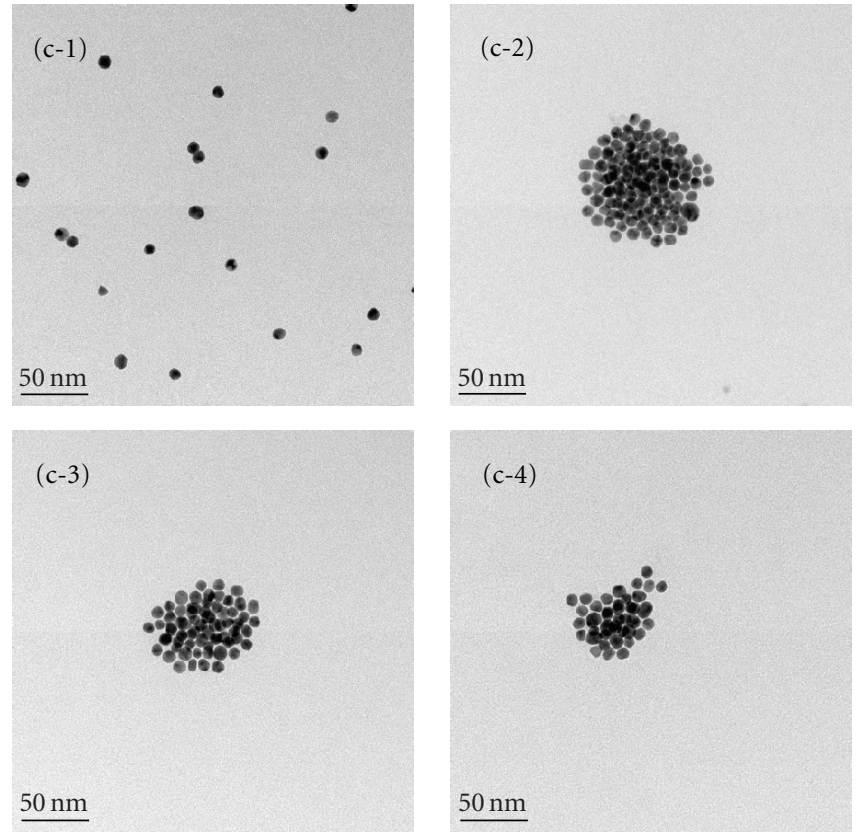

(c)

FIgURE 2: (a) Schematic diagram [24, 26, 27], (b) typical absorption spectra, and (c) typical TEM images of bare Au, 24-base, 48-base, and 72-base DNA-linked gold nanoparticle assembly. 
[32-36]. However, the flocculation factors of bioinspired $\mathrm{Au}$ assemblies for various sizes of $\sim 4$ to $\sim 23 \mathrm{~nm}$ were just increased comparing to extinction integration of bare $\mathrm{Au}$ colloidal nanoparticles. It indicates that spectral red shift and broadening can be major contributions to increase the flocculation factors for larger particle sizes, and damping rate decrease, and red shift are possible contributions to flocculation factor increase with smaller sizes.

The plasmon frequency shift of the DNA-linked aggregates was inversely dependent on the lengths of oligonucleotide linkers, and was directly related to the interparticle distance as well as the aggregate size. The optical properties of DNA-linked Au nanoparticle aggregates could be controlled through choice of DNA linker length within these novel structures [31]. The changes of SPR peaks between Au and $\mathrm{Au}$ hybridizations were $\sim 64,34$, and $28 \mathrm{~nm}$ for the three oligonucleotide linkers of 24,48 , and 72 base pairs, respectively. Weak red shifts and lower extinctions are probably due to the weak coupling effect between neighboring particles and less unit volume density of Au particles within hybridization as the base pair of oligonucleotide linker is increased. The flocculation of SPR spectra of $\mathrm{Au}$ aggregates was inversely proportional to the base pairs of oligonucleotide linker, which possibly could be due to weak red shift and less density instead of a shadowing effect.

\section{Concluding Remarks}

In summary, Au-biotin-avidin and DNA-linked Au nanoparticles interact biospecifically and inspire self-hybridization that creates surface plasmon coupling between neighboring particles and modifies their optical properties. Highly selective SPR properties and their flocculations of bioinspired Auassembly or Au-hybridizations have important implications for the development of colorimetric biological detection or treatment. Therefore, a combination of plasmonic optical tunability and DNA-linked Au-hybridization provides an excellent colorimetric analysis for biophotonic applications.

\section{Acknowledgments}

This work was supported by the Top Brand Research and Development Program (MKE, Basic Research for the Ubiquitous Lifecare Module Development) at the Electronics and Telecommunications Research Institute in South Korea, and the U.S. National Science Foundation (HRD-0734635, HRD-0630372, ESI-0426328/002, and EEC-0532472) and the U.S. Army Research Office (W911NF-07-1-0608) at Hampton University in the USA.

\section{References}

[1] K. Aslan, C. C. Luhrs, and V. H. Pérez-Luna, "Controlled and reversible aggregation of biotinylated gold nanoparticles with streptavidin," Journal of Physical Chemistry B, vol. 108, no. 40, pp. 15631-15639, 2004.

[2] D. Zanchet, C. M. Micheel, W. J. Parak, D. Gerion, S. C. Williams, and A. P. Alivisatos, "Electrophoretic and structural studies of DNA-directed Au nanoparticle groupings," Journal of Physical Chemistry B, vol. 106, no. 45, pp. 11758-11763, 2002.

[3] N. M. Green, "Avidin," Advances in Protein Chemistry, vol. 29, pp. 85-133, 1975.

[4] R. Blankenburg, P. Meller, H. Ringsdorf, and C. Salesse, "Interaction between biotin lipids and streptavidin in monolayers: formation of oriented two-dimensional protein domains induced by surface recognition," Biochemistry, vol. 28, no. 20, pp. 8214-8221, 1989.

[5] J. N. Herron, W. Müller, M. Paudler, H. Riegler, H. Ringsdorf, and P. A. Suci, "Specific recognition-induced self-assembly of a biotin lipid/streptavidin/fab fragment triple layer at the air/water interface: ellipsometric and fluorescence microscopy investigations," Langmuir, vol. 8, no. 5, pp. 1413-1416, 1992.

[6] X. Li, K. Tamada, A. Baba, W. Knoll, and M. Hara, "Estimation of dielectric function of biotin-capped gold nanoparticles via signal enhancement on surface plasmon resonance," Journal of Physical Chemistry B, vol. 110, no. 32, pp. 15755-15762, 2006.

[7] C. S. Weisbecker, M. V. Merritt, and G. M. Whitesides, "Molecular self-assembly of aliphatic thiols on gold colloids," Langmuir, vol. 12, no. 16, pp. 3763-3772, 1996.

[8] M. Sastry, N. Lala, V. Patil, S. P. Chavan, and A. G. Chittiboyina, "Optical absorption study of the biotin-avidin interaction on colloidal silver and gold particles," Langmuir, vol. 14, no. 15, pp. 4138-4142, 1998.

[9] S. Berchmans, P. J. Thomas, and C. N. R. Rao, "Novel effects of metal ion chelation on the properties of lipoic acid-capped $\mathrm{Ag}$ and Au nanoparticles," Journal of Physical Chemistry B, vol. 106, no. 18, pp. 4647-4651, 2002.

[10] S. Razin, "DNA probes and PCR in diagnosis of mycoplasma infections," Molecular and Cellular Probes, vol. 8, no. 6, pp. 497-511, 1994.

[11] J. G. Hacia, L. C. Brody, M. S. Chee, S. P. A. Fodor, and F. S. Collins, "Detection of heterozygous mutations in BRCA1 using high density oligonucleotide arrays and two-colour fluorescence analysis," Nature Genetics, vol. 14, no. 4, pp. 441449, 1996.

[12] F. S. Santiago, A. V. Todd, N. J. Hawkins, and R. L. Ward, "Detection of K-ras point mutation by enriched PCRcolorimetric plate assay," Molecular and Cellular Probes, vol. 11, no. 1, pp. 33-38, 1997.

[13] N. R. Jana, L. Gearheart, and C. J. Murphy, "Wet chemical synthesis of high aspect ratio cylindrical gold nanorods," Journal of Physical Chemistry B, vol. 105, no. 19, pp. 40654067, 2001.

[14] K. C. Grabar, R. G. Freeman, M. B. Hommer, and M. J. Natan, "Preparation and characterization of Au colloid monolayers," Analytical Chemistry, vol. 67, no. 4, pp. 735-743, 1995.

[15] G. Frens, "Controlled nucleation for the regulation of the particle size in monodisperse gold suspensions," Nature Physical Science, vol. 241, no. 105, pp. 20-22, 1973.

[16] J. J. Storhoff, R. Elghanian, R. C. Mucic, C. A. Mirkin, and R. L. Letsinger, "One-pot colorimetric differentiation of polynucleotides with single base imperfections using gold nanoparticle probes," Journal of the American Chemical Society, vol. 120, no. 9, pp. 1959-1964, 1998.

[17] X. Li, K. Tamada, A. Baba, W. Knoll, and M. Hara, "Estimation of dielectric function of biotin-capped gold nanoparticles via signal enhancement on surface plasmon resonance," Journal of Physical Chemistry B, vol. 110, no. 32, pp. 15755-15762, 2006.

[18] M. L. Sauthier, R. L. Carroll, C. B. Gorman, and S. Franzen, "Nanoparticle layers assembled through DNA hybridization: characterization and optimization," Langmuir, vol. 18, no. 5, pp. 1825-1830, 2002. 
[19] C. J. Loweth, W. B. Caldwell, X. Peng, A. P. Alivisatos, and P. G. Schultz, "DNA als Geriist zur Bildung von Aggregaten aus Gold-Nanokristallen," Angewandte Chemie International Edition, vol. 38, no. 12, pp. 1808-1812, 1999.

[20] G. Schmid and A. Lehnert, "The complexation of gold colloids," Angewandte Chemie International Edition, vol. 28, no. 6, pp. 780-781, 1989.

[21] B. Sweryda-Krawiec, H. Devaraj, G. Jacob, and J. J. Hickman, "A new interpretation of serum albumin surface passivation," Langmuir, vol. 20, no. 6, pp. 2054-2056, 2004.

[22] K. Nakanishi, T. Sakiyama, and K. Imamura, "On the adsorption of proteins on solid surfaces, a common but very complicated phenomenon," Journal of Bioscience and Bioengineering, vol. 91, no. 3, pp. 233-244, 2001.

[23] F. Fang and I. Szleifer, "Kinetics and thermodynamics of protein adsorption: a generalized molecular theoretical approach," Biophysical Journal, vol. 80, no. 6, pp. 2568-2589, 2001.

[24] J. J. Storhoff, A. A. Lazarides, R. C. Mucic, C. A. Mirkin, R. L. Letsinger, and G. C. Schatz, "What controls the optical properties of DNA-linked gold nanoparticle assemblies?" Journal of the American Chemical Society, vol. 122, no. 19, pp. 4640-4650, 2000.

[25] K. Aslan and C. D. Geddes, "Microwave-accelerated ultrafast nanoparticle aggregation assays using gold colloids," Analytical Chemistry, vol. 79, no. 5, pp. 2131-2136, 2007.

[26] L. M. Dillenback, G. P. Goodrich, and C. D. Keating, "Temperature-programmed assembly of DNA: Au nanoparticle bioconjugates," Nano Letters, vol. 6, no. 1, pp. 16-23, 2006.

[27] J. J. Storhoff, R. Elghanian, R. C. Mucic, C. A. Mirkin, and R. L. Letsinger, "One-pot colorimetric differentiation of polynucleotides with single base imperfections using gold nanoparticle probes," Journal of the American Chemical Society, vol. 120, no. 9, pp. 1959-1964, 1998.

[28] K. S. Mayya, V. Patil, and M. Sastry, "On the stability of carboxylic acid derivatized gold colloidal particles: the role of colloidal solution $\mathrm{pH}$ studied by optical absorption spectroscopy," Langmuir, vol. 13, no. 15, pp. 3944-3947, 1997.

[29] M. Quinten and U. Kreibig, "Optical properties of aggregates of small metal particles," Surface Science, vol. 172, no. 3, pp. 557-577, 1986.

[30] G. Mie, "Beiträge zur Optik trüber Medien, speziell kolloidaler Metallösungen," Annalen der Physik, vol. 330, no. 3, pp. 377445, 1908.

[31] A. A. Lazarides and G. C. Schatz, "DNA-linked metal nanosphere materials: structural basis for the optical properties," Journal of Physical Chemistry B, vol. 104, no. 3, pp. 460467, 2000.

[32] U. Kreibig and C. von Fragstein, "The limitation of electron mean free path in small silver particles," Zeitschrift für Physik, vol. 224, no. 4, pp. 307-323, 1969.

[33] S. Link and M. A. El-Sayed, "Size and temperature dependence of the plasmon absorption of colloidal gold nanoparticles," Journal of Physical Chemistry B, vol. 103, no. 21, pp. 42124217, 1999.

[34] H. Hövel, S. Fritz, A. Hilger, U. Kreibig, and M. Vollmer, "Width of cluster plasmon resonances: bulk dielectric functions and chemical interface damping," Physical Review B, vol. 48, no. 24, pp. 18178-18188, 1993.

[35] J. H. Hodak, I. Martini, and G. V. Hartland, "Spectroscopy and dynamics of nanometer-sized noble metal particles," Journal of Physical Chemistry B, vol. 102, no. 36, pp. 6958-6967, 1998.
[36] C. Voisin, N. D. Fatti, D. Christofilos, and F. Vallee, "Ultrafast electron dynamics and optical nonlinearities in metal nanoparticles," Journal of Physical Chemistry B, vol. 105, no. 12, pp. 2264-2280, 2001. 

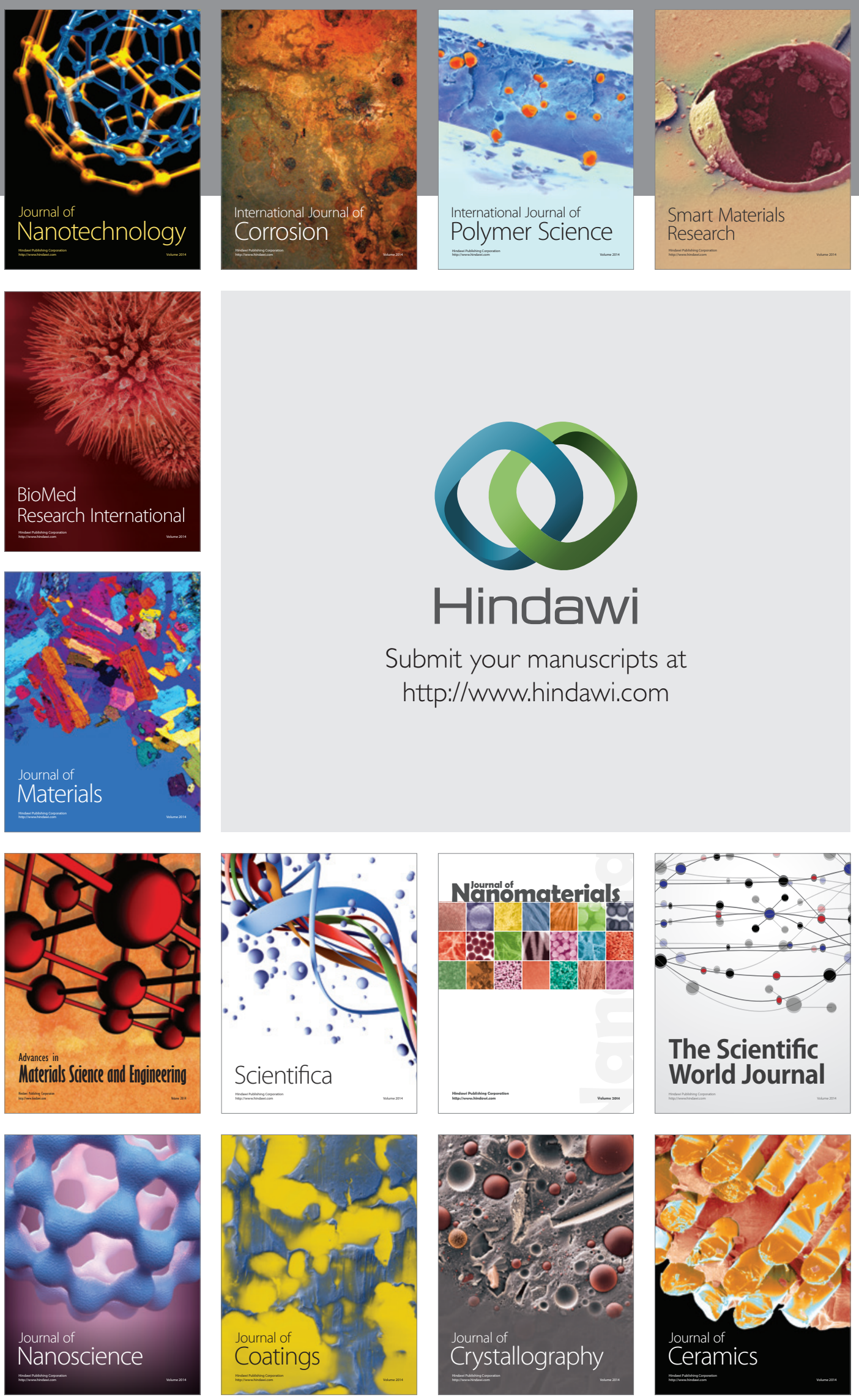

The Scientific World Journal

Submit your manuscripts at

http://www.hindawi.com

\section{World Journal}

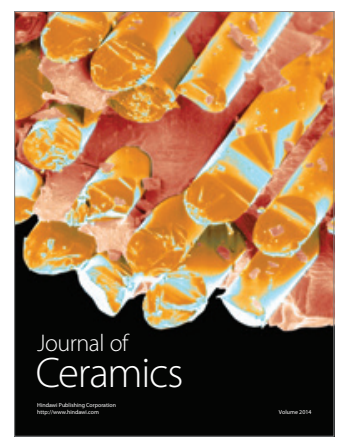

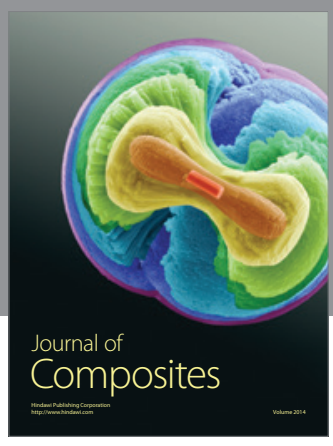
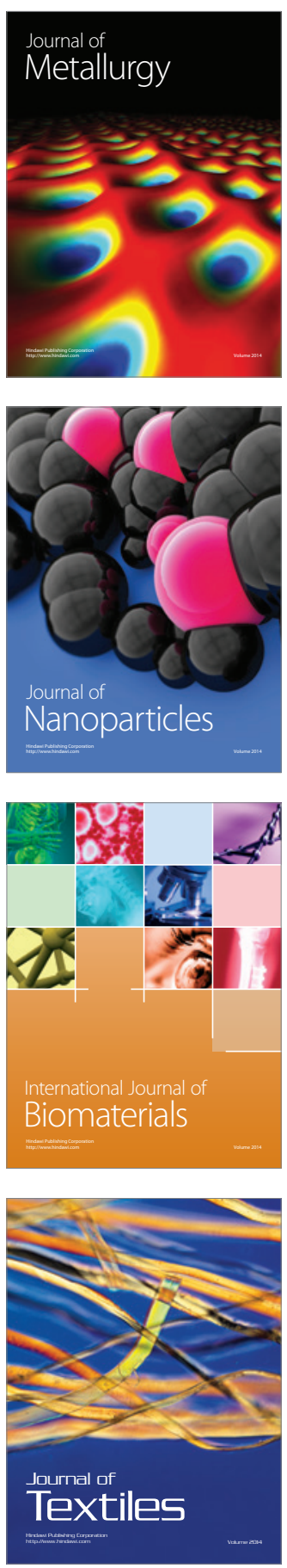